\title{
Erratum to: Tests of the harassment-reduction function and frequency-dependent maintenance of a female-specific color polymorphism in a damselfly
}

\author{
Mingzi Xu • Ola M. Fincke
}

Published online: 1 September 2011

(C) Springer-Verlag 2011

Erratum to: Behav Ecol Sociobiol (2011) 65:1215-1227

DOI 10.1007/s00265-010-1134-6

Unfortunately in the Reference the wrong article, Bots et al (2008) is cited.

The correct reference is:

Bots J, De Bruyn L, Van Damme R, Van Gossum H (2008) Effects of phenotypic variation onto body temperature and flight activity in a polymorphic insect. Physiol Entomol 33: 138-144

The online version of the original article can be found at http://dx.doi. org/10.1007/s00265-010-1134-6.

M. Xu $(\bowtie) \cdot$ O. M. Fincke

Ecology and Evolutionary Biology Program,

Department of Zoology, University of Oklahoma,

Norman, OK 73019, USA

e-mail: xumingzi@ou.edu 